\title{
CONSIDERACIÓN FILOSÓFICA DEL DERECHO A LA INFORMACIÓN Y A LA HONRA
}

\author{
Fernando Moreno Valencia \\ Decano \\ Universidad Gabriela Mistral
}

Agradezco a la Universidad Católica del Norte, especialmente a doña Luz María Reyes, el haberme invitado a este ciclo de conferencias. Me siento muy honrado por ello.

Ahora, en este tema del Derecho a la Información y el Derecho a la Honra, lo que está en cuestión es el hombre primero, es la persona humana misma. Se trata de la persona, de los derechos de la persona y de los deberes de la persona. Ha habido tiempos en la historia (un período histórico relativamente largo) en los cuales se han recordado los deberes por sobre los derechos: y en otros (los tiempos nuestros) en que han sido los derechos los privilegiados, olvidando, y a veces como en desmedro de los deberes.

Entre derecho y deberes hay una reciprocidad, ya sea a nivel de cada persona o entre las mismas personas. Yo tengo el derecho a informarme, pero tengo también el deber de informarme. $Y$ el derecho a la honra implica que si yo lo reclamo, -el derecho que yo tengo-, practique en relación a los demás, también ese respeto.

Cuatro juicios quiero enunciar aquí, de entrada.

El derecho a ser honrado y deber de honrar a otros, es el de preservar el bien que en la persona es el objeto que causa la honra. La honra de la persona proviene del bien. El merecimiento de la honra, supone un bien en la persona. Hay aquí un punto importante para la relación entre derecho a la información y derecho a la honra. Piénsese en una información que delate un vicio o el mal en una persona que sin embargo es honra$\mathrm{da}$, incluso venerada, por suponerle la virtud contraria. Bueno, esa información puede ser purificadora, supuesta la prudencia desde luego. Ahora, si la información es mentirosa, o si no corresponde la realidad, por supuesto ahí hay una deshonra indebida en relación a la persona. Queda en pie que la honra supone el bien, y que se trata, en el derecho a la honra, de preservar el bien que hay en la persona. Así, el reconocimiento al mismo tiempo implica una preservación. Está en juego aquí el principio filosófico que enuncia la preservación del ser: en definitiva, el de la misma persona. En cierto modo el derecho a la honra prima por sobre el derecho a la información; y esto, porque tiene que ver con la preservación de la persona en el sentido que estoy diciéndolo ya; y con la preservación social de la identidad, o de la imagen si se quiere, en términos más corrientes. De la identidad de la persona una vez más en cuanto al bien, a las virtudes que hay en ella. Esto no prejuzga de la exigencia de reconocer al otro en su dignidad al 
menos natural, y de asumir sus normales exigencias en el orden social. Reconocer al otro en su dignidad, proviene del simple hecho de ser persona primero.

El derecho a la información se fundamenta en el derecho natural a buscar la verdad, lo que supone como decía Santo Tomás de Aquino "suprimir la ignorancia". Existe también el deber de información, de ser informado, de informarse. Uno y otro se relacionan con la capacidad, con la formación personal: con la capacidad del hombre, del homo sapiens, para situarse y relacionarse socialmente. Todas las otras condiciones iguales, se puede decir que a mayor información, cuando la información es propia, mayor responsabilidad. La persona más informada está más obligada a responder, a dar respuesta a...; hay una mayor responsabilidad en ella. Entonces, la información se relaciona con la capacidad del homo sapiens para ejercer las libertades, para llegar a ser libre.

Todos los derechos convergen en la libertad. Si es cierto que el hombre es, como decía un filósofo francés, "un núcleo de libertad"; si es cierto que la libertad lo define, porque es racional, por ser la razón causa de la libertad, entonces los derechos se expresan en las libertades; no tiene sentido hablar de derechos, en definitiva, si no es en función de la libertad.

Precisemos aún : la información debe ser privada y pública. En relación a esta última, a la información pública, un revolucionario francés, Robespierre, decía ser aquella "el sostén de la virtud, la salvaguardia de la verdad, el terror del crimen, el azote de la intriga". Cito a Robespierre aquí porque aun en la exageración del revolucionario, hay algo de verdad. Ahora un texto más sereno, más mesurado, que voy también a referir a este propósito, dice "Existe un enorme caudal de evidencia que sugiere que los individuos capaces de razonar sobre diversos asuntos y que pueden resolver los problemas con una visión de amplio alcance, actuando como pensadores críticos y aprendices permanentes, son sin excepción personas bien informadas". Esto lo tomo en el sentido moral, no sólo sicológico. No son bien informadas en el sentido técnico de disponer de la información necesaria para realizar un objetivo, pudiendo ser cualquiera el objetivo. No, es en el sentido moral, sobre todo, que se debe estar bien informado: informado en la verdad y en el bien que se debe hacer a partir de la verdad. Esto define la libertad. Y se puede decir que el derecho a la honra y el derecho a la información, se relacionan primeramente en la verdad más que con la verdad.

\section{Algunas consideraciones complementarias al respecto.}

La verdad y el bien no se oponen, -decía Santo Tomás de Aquino-, son recíprocamente "convertibles uno en el otro". La verdad (y aquí está la dificultad precisamente de decir la verdad), implica siempre en el orden social una especie de catarsis, de purificación. Sin embargo la función del "decidor de verdad" (Arendt) es probablemente la más importante en una cultura; no sólo en la política, pero también en la política, que es probablemente el ámbito de la mayor dificultad; porque la verdad choca ahí con el poder; choca con los que tienen el poder.

Esa catarsis es la que operó ya históricamente Sócrates, quien fue un "decidor de verdad". Sócrates dice en "La Apología", argumentando en contra de sus acusadores (uno de los cuales era un connotado sofista, es decir un mentiroso) : "Yo siempre he dicho la verdad". Es una función fundamental en una sociedad el decir la verdad; y si la información no se ubica en esa perspectiva, en esa exigencia, va a dejar de cumplir su 
función propia, y va a ir en contra de la exigencia fundamental de sus mismos principios.

Aquí se plantea el problema de la sanción al "decidor de verdad". Hay distintas formas de sanción; de la sanción simplemente sico-cultural, del medio, a la sanción penal, definida legalmente. Desgraciadamente, hay posibilidad siempre de recurrir a instancias legales que permitan sancionar a un "decidor de verdad". No ya sólo al que diga cualquier cosa, sino a quien por amor a la verdad, denuncia ; porque muchas veces el decir la verdad implica denunciar. En el orden humano no puede ser de otra manera, puesto que no vivimos en el Paraíso, ni los hombres están exentos del mal y del pecado. Siempre vamos a tener que estar denunciando, delatando. En esto hay que tener cuidado, por supuesto; porque se puede ser fariseo también en estas denuncias. A veces, hay que delatarse a uno mismo o callarse. En el orden político, el abuso del poder lleva a menudo a sancionar injustamente al denunciante, a quien denuncia en nombre de la verdad. Esta es entonces acallada a través de la sanción efectiva o de la amenaza abierta o velada. Por ahí se evita al mismo tiempo la sanción que viene desde abajo, del pueblo (en el sentido propio), hacia aquellos mismo que utilizan el poder para acallar al "decidor de verdad".

Esto se aplica, a personas, grupos e instituciones. La corrupción, y aun la crisis moral en una sociedad política, implican primero a la verdad, antes que a la misma justicia. Esto fácilmente se altera; especialmente cuando la justicia ha pasado a no ser sino un instrumento a disposición de un grupo político dominante.

Pero si la verdad está en la base de la corrupción, la mentira, el engaño, el ocultamiento, la simulación, son por consiguiente los vicios a los cuales se recurre para poder defenderse de quienes denuncian la misma corrupción.

Por otro lado, la honra no es independiente de la verdad, y no lo es primero en relación a la virtud, a la verdad que es también una virtud, a la virtud de veracidad. Como decía Santo Tomás de Aquino, "del ser hacia afuera, como se es por adentro". No simular, sino que proyectarse como uno es: decir lo que uno piensa. Al aplicar esto en un orden político y más corriente, no hablarle en un sentido a un público y en uno diverso a otro. Aquí a lo mejor hay gente que se ubica a "ese lado", y voy a tener este discurso; pero si mañana estoy con otros del "otro lado" voy a tener otro discurso. Desgraciadamente eso en política se da muy a menudo, los políticos son "artistas", diría Nietzsche. No todos, por supuesto; hay muy honrosas excepciones. Pero el artista, en esta concepción de Nietzsche al menos, simula algo; cumple un papel; para ello va a adoptar la máscara o el papel que comienza de acuerdo al público, o a las conveniencias. Sea lo que fuere, la honra tiene que ver con la veracidad, con el ser hacia afuera como se es hacia adentro, interiormente; no proyectar o simular otra imagen. Se entiende entonces por qué, a veces, en concreto, la honra, o el derecho a ser honrado no tiene fundamento. Hay gente que no merece ser honrada simplemente. Las personas no merecen ser honradas, primero, por el cargo que ocupan. El cargo que ocupan es accidental al derecho a la honra en cuanto es en la persona (considerada en sí misma y en sus cualidades) donde se funda el derecho a la honra. La persona, no por ser rey, ministro, presidente de la república, lo que sea, merece ser honrada como persona y ahí es donde se juega la exigencia en relación al reconocimiento de esa persona. Lo cual no significa ignorar la importancia relativa del cargo en relación a la misma honra. Sólo que no es esto lo primero, ni lo principal. 
También, a propósito de la honra, se debe decir que toda persona tiene derecho a la verdad de su propia persona y a la de sus actos. No se debe confundir por otra parte la honra con la fama, con el prestigio, con la gloria, en el sentido en que Thomas Hobbes lo reduce, o lo entiende. En cierto modo Hobbes suplanta la honra por la gloria, entendida como una especie de aureola que engloba y eleva al sujeto a partir de su astucia. Hay que pensar que Hobbes, se ubicaba en el surco de Maquiavelo. Hobbes tiene hoy día mucha actualidad, en cuanto existe una astucia lingüística, que tiene que ver con el jugar con las palabras ("El Leviatán"); y jugar con las palabras para engañar, para simular. Es importante saber descubrir esto en los distintos ámbitos de la existencia y de la vida humana.

Volvemos entonces a la información, la cual tiene su fundamento en el derecho, como decíamos antes, a conocer la verdad, que se define como adecuación, como ajuste entre la inteligencia y la cosa. Santo Tomás de Aquino recuerda que es uno de los principios fundamentales y exigencias mayores de la ley de naturaleza, de la ley natural. Es este un derecho específico del hombre en el principal de los tres órdenes que Santo Tomás en la Suma de Teología determina. Es un derecho específico que le corresponde al hombre sólo: que no tiene el hombre en común con los animales. Es este, mejor dicho, un principio, antes de ser un derecho, un principio que le corresponde sólo al hombre. Es una exigencia del hombre que funda en él un derecho. Su importancia se mide en el hecho de que el hombre tiene en la verdad su alimento más propio, y en que la verdad es la que causa la libertad, es decir, el ser libre de la persona humana. La falsedad, el engaño, la mentira, la hipocresía, la demagogia, degradan a su agente y poluyen la cultura y la sociedad. Además, en el hombre, en el homo sapiens, la información no puede no situarse en la perspectiva de la formación de la persona, es decir, una vez más de la misma verdad; porque nadie se forma, en el sentido propio, sino en la verdad y en el bien.

Por otra parte, ambos derechos se relacionan con la justicia o se refieren a la justicia. Recordemos que la justicia es darle a cada cual lo suyo; aquí están incluídas todas las formas de justicia: la que a cada cual da lo que le corresponde, lo suyo, lo debido. La justicia, la forma que ya Aristóteles designaba como justicia de los contratos: la que Santo Tomás Ilamara justicia legal, o general, dirá él, y la justicia distributiva, que tiene que ver con la distribución de los bienes. El ejercicio de todos los derechos y deberes correlativos promueve al hombre como ser libre en la justicia. En el orden humano el ejercicio de la libertad supone la justicia. La justicia es la condición social de la libertad. La relación entre libertad y justicia resume así los derechos y deberes de la persona humana, en cuanto, primero, la libertad es el fin del hombre; segundo, la justicia y la libertad al mismo tiempo son el fin de la sociedad. Ambas son socialmente inseparables. Aunque no se pueda decir que la justicia y la libertad son, en el mismo plano, el fin del hombre El fin del hombre es la libertad, el ser libre. Es en el ejercicio de las libertades donde llega a ser lo que él ya es de alguna manera. Píndaro, cinco siglos antes de Cristo, exhortaba al hombre a "llegar a ser lo que es"; es decir, a llegar a ser libre. Para lo cual, es preciso que su libre albedrío, su capacidad de elegir entre alternativas, fructifique efectivamente en orden al bien, que es la causa final y definitiva de la libertad. Yo no soy libre eligiendo cualquier cosa, por consiguiente; en el ejercicio del libre albedrío yo me puedo hacer esclavo si no elijo lo que corresponde al bien. Ahora, por ser la libertad el fin del hombre, la libertad y la justicia, y de alguna manera la justicia por la libertad, son el fin de la sociedad al mismo tiempo. Al mismo tiempo tam- 
bién hay que tener cuidado no puedo deducir que hay que ser primero libres, y después aplicar la justicia. No se aplica la justicia después, eso también hay que decirlo con toda claridad; pero ¡cuidado con mitificar la justicia! Así lo hicieron los revolucionarios franceses; uno de los primeros y más nefastos modelos, a este propósito.

De la mitificación de la justicia (no de la libertad), proviene la mitificación de los "derechos de la persona". Todas estas, de suyo son cosas muy nobles. Es preciso promover y defender los derechos de la persona. Pero no es a través del mito o de la ideología como se van a proteger los derechos de la persona. El "justicierismo" jacobino o bolchevique, aún el "democratismo" contemporáneo, invocando los "derechos humanos" han atentado y todavía atentan -más o menos radicalmente- contra la verdad, la libertad y la justicia, es decir, contra la persona humana y sus reales derechos. Entonces, debe primar siempre la libertad, en el mismo orden empírico-social. Si acepto que la persona se define por la libertad, no puedo, optando aparentemente por la justicia, sacrificar la libertad, porque con la libertad estoy sacrificando a la persona misma. Hay una denuncia profunda de esto en Solyenitzin, especialmente en "El Archipiélago Gulag". La pretensión de absolutizar la justicia conduce a la más grave de las injusticias, porque lleva a negarle al hombre lo que le es más profundamente debido, es decir, las condiciones sociales del ejercicio de las libertades para llegar a ser libre. Pero, también la prudencia está implicada aquí, y no podría no estarlo.

\section{Algunas breves observaciones quiero hacer a este propósito.}

La prudencia es la recta determinación racional del acto, de lo que tengo que hacer aquí y ahora; es una virtud intelectual, pero también moral. Es la virtud concretizadora decía Aristóteles; realizadora. Prudencia y justicia son dos virtudes diversamente generales. La prudencia condiciona la realización justa del acto justo. Más fundamentalmente, de la prudencia depende la verdad del acto concreto. La prudencia es muy difícil en su aplicación, porque se realiza en la oscuridad de lo particular, de lo concreto de cada caso. El consejo es muy fundamental para la prudencia. Pero el consejo en su sentido propio. Ya que, a veces estamos llenos de "consejeros", que son cualquier cosa menos consejeros en orden a la virtud y el bien.

Desde aquí, desde la convergencia entre verdad, libertad, justicia y prudencia se replantea y precisa una distinción que me parece importante agregar, entre lo público y lo privado, y esto en relación tanto al hombre común como al hombre "público". En el caso de este último, del hombre público, se debe distinguir todavía entre el hombre que es publico por sus "merecimientos" (merecimientos que implican al mismo tiempo la honra, como ya lo hemos señalado) y el hombre que es público sólo por ser delegado o "representante". Hay veces en las cuales efectivamente se dan las dos cosas: en que el hombre que llega a ser delegado o representante lo es por sus virtudes o "merecimientos", o adquiere en el ejercicio de su función los "merecimientos" que exigen su reconocimiento y su ser honrado. Es en el hombre público delegado y representante, donde la "hipoteca" de su privacidad es mayor: por ser precisamente representante, alguien que hace presente a "otro". No quiero decir que se anule simplemente su privacidad ; pero hay aquí una hipoteca mayor. En el otro caso, en el del hombre público por sus puros "merecimientos", la cosa es distinta. Puede ser que incluso, en este caso, los derechos a la privacidad sean superiores. La prudencia va a determinar en casa caso. Aparece aquí hasta qué punto, en todo lo que hemos dicho, información y honra no son en absoluto ajena la una a la otra. La correcta información sobre perso- 
nas, actos, acontecimientos y situaciones es exigida por la verdad misma que debe ser dicha, por la justicia y por la honra de las personas objetivamente implicadas por la información. Hay que decir, con Sócrates, que una injusticia degrada más a su agente que a su paciente.,.

Pasemos a considerar los límites inherentes a los derechos que nos han estado ocupando. Todo derecho supone orientación a un bien particular debido. Hay aquí una limitación positiva inherente a cada derecho, el derecho a la honra es derecho a la honra, el derecho a la información es derecho a la información. Ahora, esto no quiere decir que haya separación o pura autonomía entre estos derechos. Hay un convergencia siempre, como en el caso de la virtudes. Convergen en definitiva en el sujeto; es esta la convergencia más fundamental, antropológica. Es la persona, en la consecución de su bien, la que exige una delimitación de ámbitos. El derecho a la asociación o el derecho a la reunión, por ejemplo, son derechos específicos y no se les puede confundir ni desproporcionar en su importancia. Están ligados en realidad a derechos más fundamentales: buscar la verdad, comunicar la verdad, decir la verdad, muy particularmente.

Una delimitación complementaria proviene del hecho que todo derecho supone un deber correlativo, como ya lo hemos señalado. Esto en cierta forma hipoteca el ejercicio del mismo derecho. Los deberes entonces operan como condicionamientos, subjetivos y objetivos. Obligan al ajuste entre derechos y deberes en el sujeto mismo, así como entre diversos sujetos, sometidos a una reciprocidad normativa. Tengo derecho a buscar la verdad; pero también el deber de buscarla. Tengo derecho a decirla, socialmente; pero también tengo el deber de escucharla y acogerla.

Hasta cierto punto, se puede decir que los derechos son limitados en su alcance y en su ejercicio, por la ley de naturaleza, considerada tanto en su sentido amplio (y supuesta la armonía del universo), como en el sentido específico de ley natural humana. Esta no es invención del Cristianismo ni menos de la Iglesia Católica como algunos piensan simplificadamente. Los que han criticado el iusnaturalismo, o los que se separaron de él ya desde ya desde el siglo XVI, argumentan desde una perspectiva en la que se ha perdido el sentido del ser, y en la que el voluntarismo ha suplantado al realismo del conocimiento. La naturaleza es reducida entonces a un puro mecanismo (Descartes). $Y$ la ley a no ser sino norma reguladora de esa "estructura", y, complementariamente (ley civil), mero producto de la voluntad del soberano (Hobbes). Entonces el ordenamiento de la sociedad que proviene del Estado y del poder de que éste dispone arbitrariamente, ad libitum. Sin embargo, en la tradición más clásica de la filosofía, de la literatura, uno se encuentra permanentemente con el derecho natural y con la ley de naturaleza. Se quiera o no, aún están los poetas griegos, Sócrates, Aristóteles, todo el estoicismo, y antes el caso espectacular de Sófocles'(Antígona). A veces se aduce que el iusnaturalismo es un producto de la cultura occidental, greco-romana. Pero la ley natural está en los 4 Libros de la Sabiduría de Confucio, lo que no tiene nada que ver con la cultura helénica y que le es incluso anterior, porque, como es sabido, seis siglos antes de Cristo, Confucio codifica una sabiduría, ya milenaria. Tampoco es ajena a la ley natural la sabiduría india o hindú. Basta en este caso considerar, los aforismos del Bagadavgita. La ley de naturaleza, es muy dificil "sacársela de encima", porque no nos podemos "sacar de encima" a nosotros mismos en definitiva. Así, se la reconozca o no, los derechos provienen de la ley natural, como la prueba en su obra "Los Derechos del Hombre y la Ley Natural", Jacques Maritain, el filósofo cristiano de la democracia, que no es el ideólogo de ningún partido político, y que ha sido un eximio metafísico antes que ser 
un filósofo de la política. Más que "límite", la Ley Natural es aquí origen y fundamento ; es en la ley de naturaleza donde se constituye el sujeto personal. La ley de naturaleza es, en relación a toda otra ley, norma normans, la norma que norma (no, norma normata, no la norma que es normada). No hay ninguna ley positiva, civil, que sea tal, que sea ley, que merezca el nombre de ley si no se ajusta a la ley de naturaleza, que no provenga de la ley de naturaleza. No basta con la ley de naturaleza, por supuesto, para determinar la forma de la ley civil, pero la ley de naturaleza es la raíz que se necesita para que el "árbol" exista y crezca. Si no tengo la semilla no voy a tener el árbol, pero hay que poner "agua" también, para que la semilla fructifique.

Finalmente, el bien común es una limitación en el ejercicio de los derechos; limitación positiva, porque el bien no se opone al bien. En un sentido fundamental, normativo, directo, inherente, se puede hablar aquí de una limitación antropológica. Y esto, en la medida misma en que el bien común, que es el fin de la sociedad, como un todo, proviene de las personas; es una exigencia del bien de las personas, las que son por naturaleza sociales. Naturalmente el hombre es un animal social, decía Santo Tomás, en el surco del "ZOON POLITIKON" de Aristóteles. La radical socialidad del hombre implica que su bien personal, pasa de alguna forma por el bien del todo, por el bien común, y en ese sentido el bien común es una norma fundamental.

En la reciente instrucción del Pontificio Consejo para las Comunicaciones Sociales sobre la Etica de la Publicidad, que cita al Catecismo en el número 2494, se dice lo siguiente: "La información suministrada por los medios está al servicio del bien común. La sociedad tiene el derecho a la información basada en la verdad, la libertad, la justicia y la solidaridad". Un texto del mismo Juan Pablo II, recuerda que: "EI justo ejercicio del derecho a la información reclama que el contenido de lo que se comunica sea verdad, y dentro de los límites fijados por la justicia y la caridad, sea completo". Se incluye así la obligación de evitar cualquier manipulación de la verdad, por cualquier razón, como lo exhortaba el Papa en un discurso a los especialistas de las comunicaciones, en Los Angeles, Estados Unidos, el 15 de Septiembre de 1987. Del bien común debemos decir todavía algo. Es un bien primero que nada: como tal es un fin (algo que es deseable por sí mismo), no es un medio; fin "infravalente", no fin último, por supuesto. El mismo bien común es el que exige el respeto de la honra y la debida información. Hay aquí como un movimiento circular, lo que se origina en la persona y que se proyecta en la sociedad, en el fin de la sociedad que es el bien común, vuelve sobre la persona humana, revierte sobre la persona y la capacita para actuar mejor en la misma sociedad. Aquí encontramos la noción de participación, ligada especialmente al derecho a la información.

Hablamos de la verdadera doctrina de la participación, no de la ideología participacionista, que algunos hasta hace poco invocaban. Quien definió la participación primero, en un sentido propio, fue Aristóteles en "La Política". Para Aristóteles, está claro que no hay participación sino en el bien común; y él precisa esto en relación explícita al gobierno o a la capacidad de gobernar. "Todo ciudadano debe estar disponible-decía- para el gobierno". Esto hoy día habría que aplicarlo con bastante cuidado, porque algunos se pueden entusiasmar más de la cuenta; se sienten demasiado capacitados para... No; hay una disponibilidad primero, antes que una capacidad. Si todos están disponibles, no quiere decir que todos, por ello mismo, estén capacitados para... 
Ahora bien, en relación a la información, es importante destacar que la información - hoy día más que nunca- es condición de la justa participación. Los gobernantes saben que tienen que estar informados para poder operar, ejercer su función propiamente gubernamental. $Y$ los gobernados también sabemos que tenemos que estar informados para poder participar en lo que nos corresponde, y cumplir con nuestro deber de contralores de quienes gobiernan.

La honra, por su parte, juega un papel muy importante para la participación, considerando en particular la función positiva del testimonio en la sociedad. Fácilmente hoy día se cree que la política es el buen programa, o simplemente la buena institución. La política es el buen político primero; no hay buena política si no hay buenos políticos. Y sabemos que el problema más fundamental de la política está precisamente ahí, que los buenos políticos son muy pocos, poquísimos.

Un problema que se plantea hoy en nuestro tiempo es el de la sobreabundancia, la complejidad, la dispersión y la aceleración de la información; lo que lleva a perder los puntos de anclaje que necesitamos sicológica, moral y culturalmente. Yo llamaría esto un apabullamiento por una especie de vorágine objetiva, de torbellino. El desafío aquí está, me parece a mí, en dosificar la información; porque hay un momento en que la cantidad misma perjudica el servicio al cual debe estar destinada la información; dosificar la información y proporcionar, diría yo, la comunicación. Proporcionar la comunicación, exige descubrir y profundizar teorética y prácticamente los principios de ordenamiento y de orientación. No todo es necesario que sea comunicado, en los límites de las exigencias de la verdad y del bien común.

Una vez más la virtud de prudencia es aquí fundamental. En todo caso el hombre no puede renunciar a la exigencia de "situarse" y de actuar debidamente. La información es importantísima, fundamental para ello. En el mismo sentido, la información se relaciona con la seguridad, cuya importancia para la vida humana y social vio ya (no sin exageración sin embargo) Platón en "La República". La utopía que es "La República" nos habla de una sociedad perfecta, donde todo está integrado, y todo está asegurado. Más tarde Hobbes lo planteó desastrosamente, a mi modo de ver, en "El Leviatán"; anticipando la ideología totalitaria. Pero hay una manera de concebir la seguridad como exigencia de la persona y del bien común que es propia. La seguridad, en este caso, no supone alterar ninguna de las virtudes o de las formas políticas institucionales y legales que son exigidas por la misma justicia, por las virtudes y por la verdad. La información aporta al bienestar, a la seguridad, y más ampliamente, a la realización del bien común. 